\title{
A brief overview of the past, present, and future of the Department of General Surgery at Pietersburg and Mankweng hospitals in Limpopo Province, South Africa
}

\author{
${ }^{1}$ Department of General Surgery, Mankweng hospital, University of Limpopo, South Africa \\ ${ }^{2}$ Department of General Surgery, Pietersburg Hospital, University of Limpopo, South Africa
}

M M Z U Bhuiyan, ${ }^{1}$ MB ChB, DTH, FRCS (Glasgow), MMed; A B van As, ${ }^{2}$ MB ChB, FCS (SA), MMed, MBA, PhD

Corresponding author: A B van As (sebastian.vanas@uct.ac.za)

S Afr Med J 2021;111(11b):1120-1121. https://doi.org/10.7196/SAMJ.2021.v111i11b.16099

\section{Past}

It is no secret that there has been a paucity of medical care facilities in rural areas. In 1978, the Medical University of South Africa (Medunsa) was established to alleviate this situation by training black doctors, dentists, and other health professionals - at that time over $90 \%$ of medical personnel were white. ${ }^{[1]}$

Ga-Rankuwa Hospital (currently the Dr George Mukhari Hospital) was established in 1973 but was converted to an academic centre and the university's first teaching hospital in 1978, and at the time it consisted of 39 wards and had $>2000$ beds, making it the second largest hospital in the southern hemisphere.

Although academic publications were limited, the Department of Surgery established its name in the fields of thyroid and peptic ulcer disease.

Under significant duress and as part of a nationwide restructuring, Medunsa entered a forced but brief marriage with the University of the North (currently the University of Limpopo), whereby both Pietersburg and Mankweng hospitals became established academic satellite hospitals. At that time, there were only 2 general surgeons working in Polokwane; the other surgical specialties were not represented.

Pietersburg Hospital dates to the Anglo-Boer war, when a military hospital consisting mainly of corrugated iron was established to treat soldiers. Women and children were accommodated in their own wards at the hospital. A permanent and well-equipped hospital was finally built and opened in 1927. The geographic challenges were recognised early and after some lobbying, the International Red Cross donated the first ambulance, a 1929 model Chevrolet (Fig. 1).

The current Pietersburg Hospital opened in 1978, followed by the opening of Mankweng Hospital in 1988. There have been many illustrious heads of department in General Surgery, but Prof. Z Machowski (1996 - 2007) deserves special mention. He was responsible for elevating the Department of General Surgery in a truly academic fashion, focusing on a rigorous teaching and learning programme, and a strong research and scientific publication count. He published over 50 articles over the duration of half a century from $1967-2017 \cdot{ }^{[2,3]}$

\section{Present}

Currently, the Limpopo Academic Complex has 6 full-time specialists in general surgery, 2 foreign-qualified consultants (MO3), 4 surgical registrars, 13 medical officers, and 16 interns. This department performs $\sim 2000$ surgical procedures and $\sim 4500$ surgical consultations annually. It also performs over 500 minor procedures in a day-case

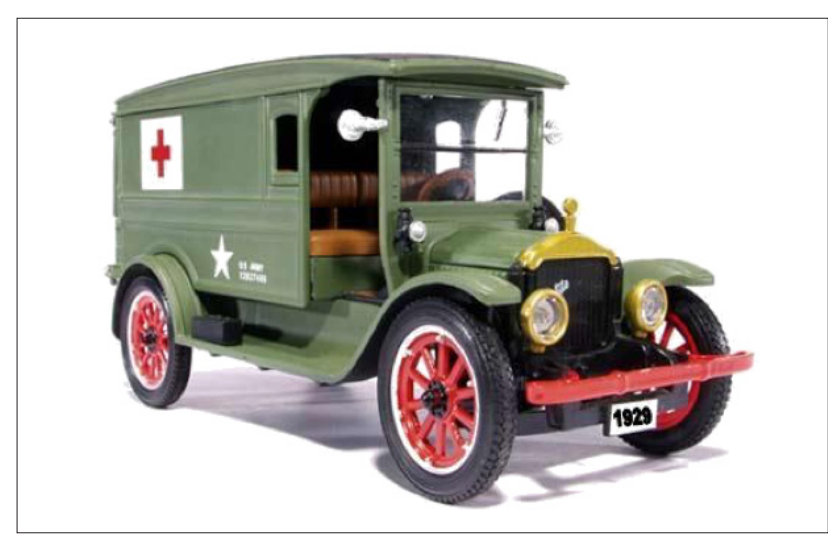

Fig. 1. A picture of the first ambulance in South Africa, a 1929 model Chevrolet, donated to Pietersburg Hospital by the International Red Cross.

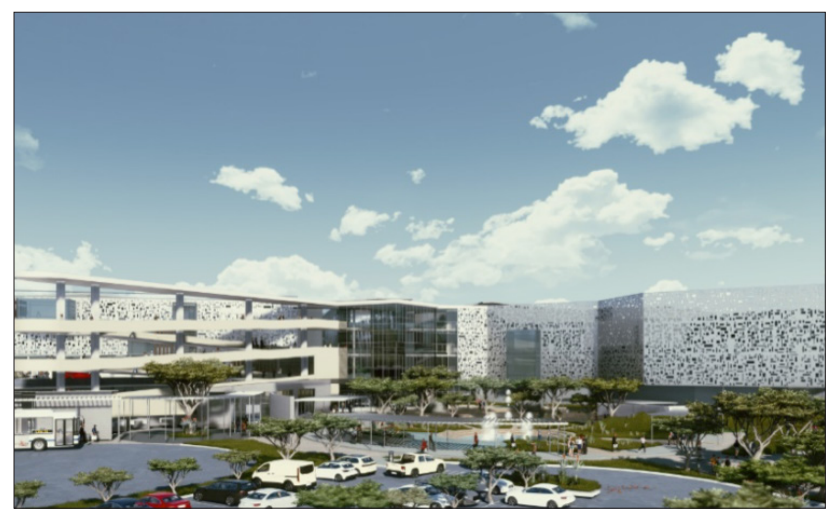

Fig. 2. The newly signed-off Limpopo Academic Health Complex. Picture courtesy of Hospital Design Group and Sakhiwo Health Solutions.

unit, receives referrals from 43 other hospitals and drains a large geographic area in Limpopo Province with over 6 million inhabitants. In addition, it provides teaching for registrars and general doctors, and it performs research and outreach for all Limpopo's hospitals. Over the last 10 years, it published 15 peer-reviewed academic manuscripts and managed to deliver over 50 academic papers at national and international congresses.

\section{Future}

Plans to build a brand-new academic complex have been approved; 
the new complex will harbour 16 state-of-the-art operating theatres and hopefully will accommodate at least 10 full-time general surgeons (Fig. 2). The Department of General Surgery has recently submitted its application to the Health Professional Council of South Africa to double the number of registrars from 8 to 16 . We are hopeful that this request will be granted, paving the way for Polokwane to become a fertile ground for training a new generation of general surgeons in South Africa. A new medical school to be constructed on site next to the hospital complex is currently planned by the University of Limpopo.

Declaration. None.

Acknowledgements. None.
Author contributions. Equal contributions.

Funding. None.

Conflicts of interest. None.

1. Mbava D, Modiba MCM. The Department of Surgery, University of Limpopo (Medunsa Campus). SAJS 2006;44(1):4-5.

2. Nielubowicz J, Olszewski W, Machowski Z, Sokolowski J. Experimental studies on the lymphaticvenous anastomosis in the extremity. Pol Przegl Chir 1967;39(9):906-911.

3. Bhuiyan MMZU, Mavhungu R, Machowski A. Provision of an emergency theatre in tertiary hospitals is cost-effective: Audit and cost of cancelled planned elective general surgical operations at Pietersburg Hospital, Limpopo Province, South Africa. S Afr Med J 2017;107(3):239-242. https://doi.org/10.7196/ SAMJ.2017.v107i3.10687

Accepted 3 September 2021. 